\title{
SPOTTED
}

\section{Spotted around the web: SHANK3 tug of war, motor issues, tenure threat}

\author{
BY JILL ADAMS, NIKO MCCARTY
}

22 OCTOBER 2021 